NBER WORKING PAPER SERIES

FINANCIAL INCENTIVES AND OTHER NUDGES DO NOT INCREASE COVID-19 VACCINATIONS AMONG THE VACCINE HESITANT

\author{
Tom Chang \\ Mireille Jacobson \\ Manisha Shah \\ Rajiv Pramanik \\ Samir B. Shah \\ Working Paper 29403 \\ http://www.nber.org/papers/w29403
}

\author{
NATIONAL BUREAU OF ECONOMIC RESEARCH \\ 1050 Massachusetts Avenue \\ Cambridge, MA 02138 \\ October 2021
}

Research reported in this paper was supported by J-PAL North America's State and Local Innovation Initiative as well as the National Institute on Aging of the National Institutes of Health under Award Number P30AG034532. The content is solely the responsibility of the authors and does not necessarily represent the official views of J-PAL North America or the National Institutes of Health. We also are grateful for extremely helpful feedback from Marcella Alsan, Wandi Bruine de Bruin, Michael Hallsworth, Elana Safran, Anya Samek, Swaroop Samek, and Mattie Toma as well as participants at the National Bureau of Economic Research's COVID-19 and Health Outcomes Spring Conference on June 16, 2021 and from ongoing support from Joe Doyle and Sarah Holmes Berk. The views expressed herein are those of the authors and do not necessarily reflect the views of the National Bureau of Economic Research.

NBER working papers are circulated for discussion and comment purposes. They have not been peer-reviewed or been subject to the review by the NBER Board of Directors that accompanies official NBER publications.

(C) 2021 by Tom Chang, Mireille Jacobson, Manisha Shah, Rajiv Pramanik, and Samir B. Shah. All rights reserved. Short sections of text, not to exceed two paragraphs, may be quoted without explicit permission provided that full credit, including $(\subset)$ notice, is given to the source. 
Financial Incentives and Other Nudges Do Not Increase COVID-19 Vaccinations among the Vaccine Hesitant

Tom Chang, Mireille Jacobson, Manisha Shah, Rajiv Pramanik, and Samir B. Shah

NBER Working Paper No. 29403

October 2021

JEL No. I12,I18

\section{ABSTRACT}

Can financial incentives, public health messages and other behavioral nudges -approaches deployed by state and local governments, employers, and health systems - increase SARS-CoV-2 vaccination rates among the vaccine hesitant in the US? In mid-2021, we randomly assigned unvaccinated members of a Medicaid managed care health plan to $\$ 10$ or $\$ 50$ financial incentives, different public health messages, a simple appointment scheduler, or control to assess impacts on SARS-CoV-2 vaccination intentions and vaccine uptake within 30 days of intervention. While messages increased vaccination intentions, none of the treatments increased overall vaccination rates. Consistent with backlash concerns, financial incentives and negative messages decreased vaccination rates for some subgroups. Financial incentives and other behavioral nudges do not meaningfully increase SARS-CoV-2 vaccination rates amongst the vaccine hesitant.

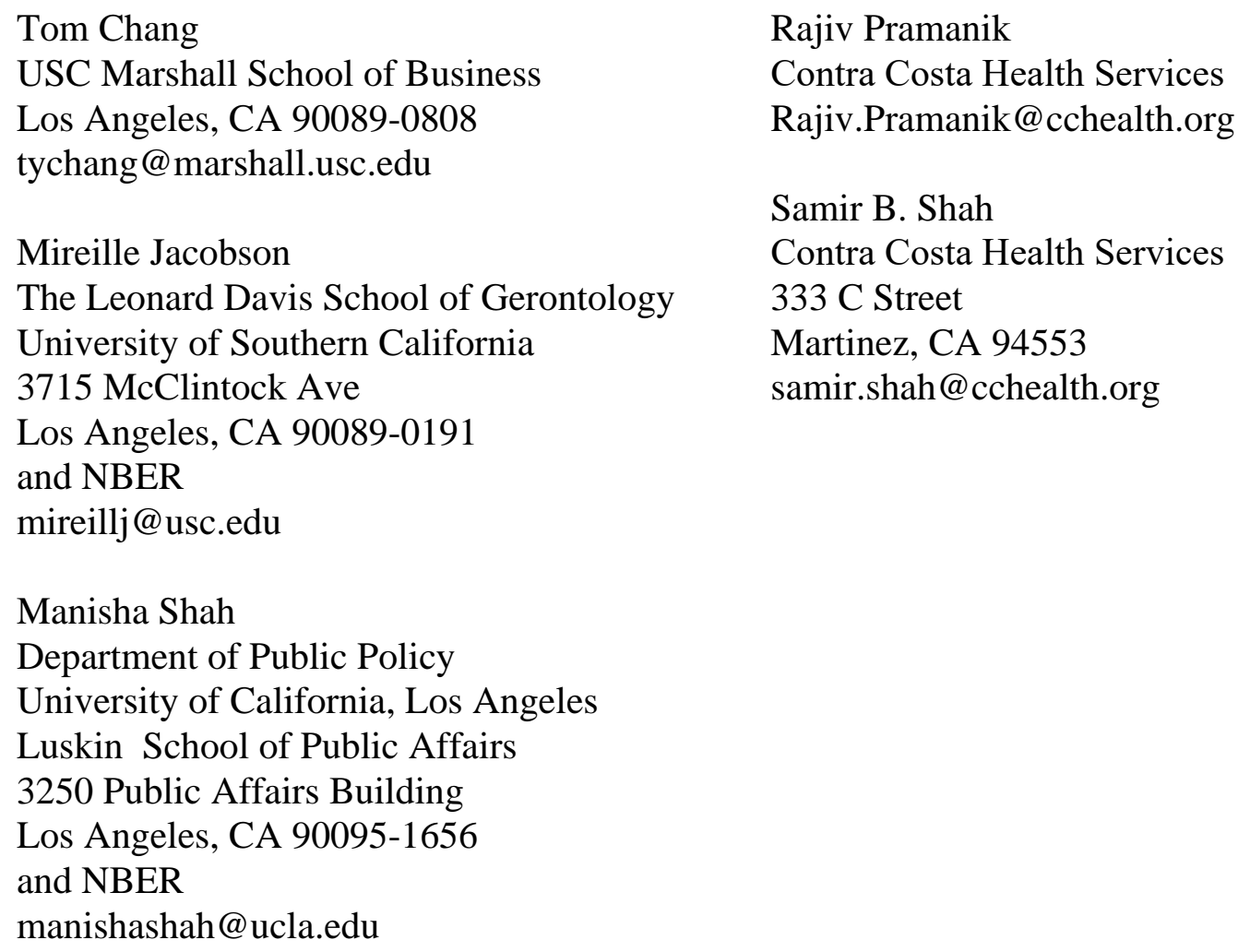




\title{
Financial incentives and other nudges do not increase COVID-19 vaccinations among the vaccine hesitant
}

\author{
Tom Y. Chang ${ }^{\mathrm{a}, 1}$, Mireille Jacobson ${ }^{\mathrm{b}, \mathrm{c}, 1}$, Manisha Shah $^{\mathrm{d}}$, Rajiv Pramanik ${ }^{\mathrm{e}}$, Samir B. Shah ${ }^{\mathrm{e}}$
}

\begin{abstract}
Affiliations:

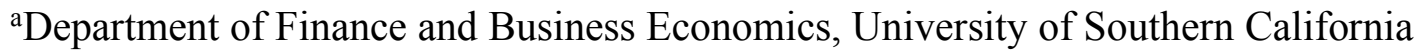

${ }^{b}$ Leonard Davis School of Gerontology, University of Southern California

${ }^{\mathrm{c}}$ Leonard Schaeffer Center for Health Policy \& Economics, University of Southern California

${ }^{\mathrm{d} D e p a r t m e n t}$ of Public Policy, University of California, Los Angeles

${ }^{\mathrm{e}}$ Contra Costa Regional Medical Center \& Health Centers, Contra Costa Health Services

${ }^{1}$ These authors contributed equally to the work.
\end{abstract}

\begin{abstract}
Can financial incentives, public health messages and other behavioral nudges approaches deployed by state and local governments, employers, and health systems - increase SARS-CoV-2 vaccination rates among the vaccine hesitant in the US? In mid-2021, we randomly assigned unvaccinated members of a Medicaid managed care health plan to $\$ 10$ or $\$ 50$ financial incentives, different public health messages, a simple appointment scheduler, or control to assess impacts on SARS-CoV-2 vaccination intentions and vaccine uptake within 30 days of intervention. While messages increased vaccination intentions, none of the treatments increased overall vaccination rates. Consistent with backlash concerns, financial incentives and negative messages decreased vaccination rates for some subgroups. Financial incentives and other behavioral nudges do not meaningfully increase SARS-CoV-2 vaccination rates amongst the vaccine hesitant.
\end{abstract}

At the height of the SARS-CoV-2 vaccination campaign in the United States, nearly 2 million people were being fully vaccinated a week (1). As of the beginning of October 2021, that number had dropped below 250,000 a week, despite ample supply of vaccine and even though over 60 million adults remain unvaccinated (2). In response to SARS-CoV-2 vaccine hesitancy, the delay or outright refusal of vaccinations $(3,4)$, many state and local governments, employers and health systems have turned to financial incentives - gift cards, saving bonds and even lotteries with grand prizes of $\$ 1$ million or higher - to increase vaccine uptake (5). Public health messages, which have shown some promise in increasing vaccination intentions $(6,7,8)$ are also widely used to combat vaccine hesitancy.

Financial incentives and other behavioral nudges, small changes to the choice environment meant to combat inattention, forgetfulness, and other psychological biases, have shown promise for increasing influenza vaccinations $(9,10,11,12,13)$. Despite considerable time, interest, and money put towards similar efforts for SARS-CoV-2 vaccinations, the evidence on their effectiveness at increasing actual vaccinations, particularly among the vaccine hesitant, remains slim. Only two randomized trials of behavioral interventions, one in the United States (14) and 
the other in Sweden (15), consider SARS-CoV-2 vaccinations as a primary outcome. The U.S. study, which found that reminder messages, specifically those that emphasized vaccine "ownership," increased vaccination rates, was conducted in February 2021 before SARS-CoV-2 vaccines were available to the general public and when vaccine supply was still limited. The other study, which found that financial incentives of just $\$ 25$ increased vaccination rates by over 4 percentage points in Sweden, focused on vaccinations within 30 days after participants became eligible for them based on their age-group. Although both studies find support for behavioral nudges in increasing vaccinations, the applicability of these findings to vaccine hesitant populations in the United States may be limited.

Quasi-experimental analyses of Ohio's Vax-a-Million lottery, which offered weekly prizes of up to $\$ 1$ million over the course of 5 weeks between the end of May and June 2021, have shown small or no impacts on vaccination rates. A comparison of Ohio to the rest of the United States suggests no impact of the lottery on vaccination rates (16) while a comparison with a constructed "synthetic control" suggests a small increase on the order of 1 percentage point (17).

Much of the current evidence on the impact of behavioral nudges on SARS-CoV-2 vaccination is survey based with the outcome being intentions as opposed to actual vaccinations (6-8).

Evidence for a link between self-reported measures of vaccination intentions and actual vaccinations is relatively sparse. In Sweden, vaccination intentions and outcomes appear closely linked (15). However, the only U.S. study we know of that looks at this link finds that vaccination intentions elicited from an online survey is not informative of actual vaccinations in a patient population (14).

We conducted a preregistered randomized control trial (AEARCTR-00007405 and NCT04867174) between May 24, 2021 and July 16, 2021 to test the impact of financial incentives, different public health messages, and an easy vaccine scheduling link on stated intentions to get vaccinated and actual SARS-CoV-2 vaccinations of members of Contra Costa Health Plan (CCHP), the public Medicaid managed care plan in Contra Costa County, California. Contra Costa County is a racially and ethnically diverse suburban Bay Area county with a population about the size of Rhode Island (18). Contra Costa has one of the highest countywide vaccination rates in California (19) and, due to increased vaccine supply from the federal government, was able to open up vaccinations to all adults at the end of March 2021 (20), several weeks in advance of the State (21). Consequently, our study focuses specifically on individuals who had delayed vaccination despite weeks of eligibility and ample supply of vaccine. Our hypothesis is that financial incentives, messaging, and the scheduling link would all increase vaccine uptake among the vaccine hesitant population.

\section{Materials and Methods}

CCHP members aged 18 and over who had previously self-identified as White, Black, or Latino and were unvaccinated based on daily reports from the California Immunization Registry (CAIR2) were randomly allocated to intervention arms using a factorial design (see Supplementary Information (SI) Appendix Figure S1). These individuals were invited via e-mail or SMS to participate in a short internet-based survey (see SI Appendix Experimental Methodology).

All survey participants watched one of three different public health video messages or no video. To assess whether video messages changed participants vaccination intentions, videos were 
played immediately before a question about vaccination intentions. The first message, which focused on getting back to normal was a publicly available video from the California Department of Public Health (CDPH message). The remaining two messages, which were developed by our team in consultation with outside medical and behavioral science experts, featured physicians from Contra Costa Regional Medical Center, the integrated public health system that is the primary health care provider for many CCHP members. One of the messages highlighted the safety of the SARS-CoV-2 vaccines ("safety" message); the other, which was inspired by a study to counter childhood vaccination misinformation (22), focused on the negative health consequences of remaining unvaccinated ("health consequences" message).

Both messages were recorded by the same set of physicians and included a White female, White male, Black female, Black male, Latina female and Latino male physician. Latino physicians recorded the messages in both English and Spanish (23). These two messages were also randomized to be race/ethnicity and gender concordant/discordant with the respondent (See SI Figure S2c and S2d).

Survey participants were also randomly assigned to receive no financial incentive or a financial incentive of $\$ 10$ or $\$ 50$ for getting vaccinated within two weeks of survey completion. A twoweek period was used based on the idea that a shorter window would lead to less procrastination and a more effective nudge. Participants were told that they had been randomly selected to receive a financial incentive only after completing the survey. Those randomized to financial incentives also received a reminder about the incentive along with their e-gift card for survey completion.

Participants were also randomly assigned to receive a highlighted convenient link to the county's new public vaccination appointment scheduling system or just a message about getting vaccinated without a link. The county scheduling system was designed to reduce scheduling frictions associated with the state of California's online vaccine scheduling system. Unlike the state's scheduling system, the county's showed appointments on the landing page and did not require the user to enter personal data before vaccination sites and times were shown. Like the financial incentive, the link appeared at the very end of the survey.

Our primary outcomes were whether a respondent received at least one dose of a SARS-CoV-2 vaccine within 30 days of survey completion and vaccination intentions, measured as a respondent's stated probability (0-100) of getting vaccinated in the next 30 days. Vaccination data for all respondents were drawn from the CAIR2 database. Our protocol was approved by the Institutional Review Board (IRB) at the University of Southern California (USC) and Contra Costa Health Service's Institutional Review Committee (IRC). USC's IRB, which took the lead in the review, granted a partial waiver of informed consent for the purpose of recruitment. Respondents signed an informed consent and a HIPAA authorization at pre-screening, prior to taking the survey.

\section{Empirical Analysis}

Unless explicitly qualified as exploratory, all analysis discussed in this section was pre-registered at the AEA. To analyze the impact of our interventions on vaccination, we estimate the following linear regression model: 


$$
\text { (1) } \text { Vaccinated }_{i}=\alpha+\beta_{1} \text { Financial }_{i}+\mathrm{M}_{i} \theta+\beta_{3} \text { Link }_{i}+\delta X_{i}+\varepsilon_{i}
$$

where Vaccinated $_{i}$ is an indicator $(0 / 1)$ for whether a respondent received a SARS-CoV-2 vaccination within one month after completing the survey. Financial $_{i}$ is an indicator for whether the individual was randomized into the financial incentive arm, $M$ is a vector of indicators for randomization into each of the three message types (CDPH, safety, or health consequences video) and $\operatorname{Link}_{i}$ is an indicator for whether the individual was randomized to receive the highlighted link. The excluded group, the control condition, received no extra prompting to get vaccinated. To increase precision, we estimate versions of (1) that include $X_{i}$, a vector of predetermined characteristics including age and its square, race, gender, self-reported income, education, the language the respondent took the survey in (English/Spanish), whether the respondent was "impaneled," meaning primary health care is provided at Contra Costa Regional Medical Center, and indicators for calendar date. Our main hypotheses are that all of the interventions will increase vaccination rates, $\beta_{1}>0, \theta>0$ and $\beta_{3}>0$.

To differentiate across the financial incentive amounts, we expand on (1) to estimate:

$$
\text { (2) } \text { Vaccinated }_{i}=\alpha+\beta_{1} 1_{i}^{\$ 10}+\beta_{2} 1_{i}^{\$ 50}+\mathrm{M}_{i} \theta+\beta_{3} \text { Link }_{i}+\delta X_{i}+\varepsilon_{i}
$$

where $1_{v}^{\$ 10}$ and $1_{v}^{\$ 50}$ are indicators for being randomized into financial incentives of $\$ 10$ or $\$ 50$. Our hypothesis is that the magnitude of the effect is increasing in the incentive amount: $0<\beta_{1}<$ $\beta_{2}$.

Our analysis of vaccinations intentions is based on a modification of equation (1):

$$
\text { Intention }_{i}=\alpha+\beta_{1} \text { Financial }_{i}+\mathrm{M}_{i} \theta+\beta_{3} \text { Link }_{i}+\delta X_{i}+\varepsilon_{i}
$$

where Intention ${ }_{i}$, a respondent's self-assessed probability of getting vaccinated in the next 30 days, takes the place of (2) Vaccinated $_{i}$. Note that since the financial incentive and scheduling link are presented to individuals after survey completion, they are included here only as indicators of treatment stratum and are not meant to generate causal estimates of their impact on vaccine intentions. Our main hypothesis is that messaging increases vaccine intentions, $\theta>0$. We further hypothesize that the health consequences message will have the largest effect on intentions such that $\theta_{3}>\theta_{1}$, and $\theta_{3}>\theta_{2}$, where 3 denotes the health consequences message, 2 denotes the safety message and 1 denotes the CDPH message.

We analyze heterogeneity in the impacts of our interventions by respondent gender, race/ethnicity, age-group, and support for Trump or Biden during the 2020 presidential election.

To analyze whether race and gender concordance affects the impact of health messages, we rerun the models specified by equations 1 and 3, but include interactions between the relevant video

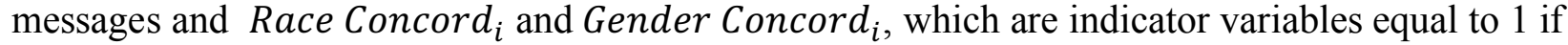
the physician messenger and the recipient share the same race/ethnicity or gender, respectively.

In exploratory analysis, we check the robustness of our results to model choice. First, we estimate probit regression models of vaccine uptake (equations (1) and (2)) and censored regression models (tobit models) of vaccination intentions (3). Unlike the linear regression model, the probit model bounds the predictions of the outcome to 0 or 1. Similarly, we estimate tobit regression models of vaccination intentions to account for the fact that intentions are censored at 0 and 100 .

\section{Results}


Survey respondents are an average of 36.4 years of age $(\mathrm{SD}=12.6), 74.3 \%$ are female, reflecting the general gender skew in Medi-Cal enrollment (24). 35.9\% self-identified as White, 30.5\% as Black, and $33.6 \%$ as Latino. $67.4 \%$ of respondents are impaneled with the county health system, Contra Costa Regional Medical Center. The median self-reported household income is between $\$ 20,000$ to $\$ 29,999$ and $8.3 \%$ of respondents have less than a high school degree. $55.4 \%$ supported Biden in the 2020 presidential election and 15.7\% supported Trump. As shown in Table 1, characteristics are generally well balanced across treatment arms; all joint tests of treatment-control differences are statistically indistinguishable from zero (25).

Table 1. Treatment-control balance. We report the control mean (with standard deviation for continuous variables) and the treatment mean difference (with p-values in parentheses) for the outcomes listed in the left-hand column. For variables that are percentages, the treatment-control difference are percentage points. The final row reports the pooled F-statistic and p-value from a joint test of treatment-control balance.

Characteristics of the analysis sample

\begin{tabular}{|c|c|c|c|c|c|c|}
\hline \multirow[b]{2}{*}{ Age } & \multicolumn{2}{|l|}{$\begin{array}{l}\text { Control } \\
\text { mean }\end{array}$} & \multicolumn{3}{|c|}{ Treatment-Control Difference } & \\
\hline & $\begin{array}{l}36.9 \\
(11.7)\end{array}$ & $\begin{array}{l}-0.91 \\
(0.410)\end{array}$ & $\begin{array}{l}-0.56 \\
(0.616)\end{array}$ & $\begin{array}{l}-0.19 \\
(0.865)\end{array}$ & $\begin{array}{l}-0.70 \\
(0.502)\end{array}$ & $\begin{array}{l}-0.65 \\
(0.539)\end{array}$ \\
\hline Female $(\%)$ & 72.8 & $\begin{array}{l}-0.40 \\
(0.924)\end{array}$ & $\begin{array}{l}0.51 \\
(0.903)\end{array}$ & $\begin{array}{l}3.64 \\
(0.384)\end{array}$ & $\begin{array}{l}2.27 \\
(0.568)\end{array}$ & $\begin{array}{l}1.94 \\
(0.629)\end{array}$ \\
\hline $\begin{array}{l}\text { English as preferred } \\
\text { language }(\%)\end{array}$ & 94.1 & $\begin{array}{l}-1.02 \\
(0.650)\end{array}$ & $\begin{array}{l}1.81 \\
(0.403)\end{array}$ & $\begin{array}{l}0.31 \\
(0.889)\end{array}$ & $\begin{array}{l}0.44 \\
(0.533)\end{array}$ & $\begin{array}{l}0.03 \\
(0.990)\end{array}$ \\
\hline Hispanic $(\%)$ & 30.9 & $\begin{array}{l}2.89 \\
(0.508)\end{array}$ & $\begin{array}{l}6.22 \\
(0.157)\end{array}$ & $\begin{array}{l}0.65 \\
(0.883)\end{array}$ & $\begin{array}{l}2.86 \\
(0.489)\end{array}$ & $\begin{array}{l}3.32 \\
(0.426)\end{array}$ \\
\hline Black (\%) & 28.7 & $\begin{array}{l}2.75 \\
(0.520)\end{array}$ & $\begin{array}{l}-2.28 \\
(0.591)\end{array}$ & $\begin{array}{l}4.13 \\
(0.339)\end{array}$ & $\begin{array}{l}1.95 \\
(0.630)\end{array}$ & $\begin{array}{l}1.91 \\
(0.640)\end{array}$ \\
\hline Impaneled (\%) & 61.0 & $\begin{array}{l}9.90 \\
(0.029)\end{array}$ & $\begin{array}{l}5.18 \\
(0.257)\end{array}$ & $\begin{array}{l}4.73 \\
(0.303)\end{array}$ & $\begin{array}{l}11.95 \\
(0.006)\end{array}$ & $\begin{array}{l}6.53 \\
(0.139)\end{array}$ \\
\hline $\begin{array}{l}\text { At least high school } \\
\text { graduate }(\%)\end{array}$ & 91.2 & $\begin{array}{l}-0.28 \\
(0.916)\end{array}$ & $\begin{array}{l}0.53 \\
(0.843)\end{array}$ & $\begin{array}{l}0.38 \\
(0.886)\end{array}$ & $\begin{array}{l}0.45 \\
(0.859)\end{array}$ & $\begin{array}{l}0.35 \\
(0.891)\end{array}$ \\
\hline $\begin{array}{l}\text { HH Income }<\$ 20,000 \\
(\%)\end{array}$ & 40.4 & $\begin{array}{l}6.25 \\
(0.177)\end{array}$ & $\begin{array}{l}1.94 \\
(0.675)\end{array}$ & $\begin{array}{l}8.13 \\
(0.082)\end{array}$ & $\begin{array}{l}5.83 \\
(0.184)\end{array}$ & $\begin{array}{l}4.40 \\
(0.321)\end{array}$ \\
\hline Supported Biden (\%) & 55.4 & $\begin{array}{l}0.50 \\
(0.914)\end{array}$ & $\begin{array}{l}-2.92 \\
(0.532)\end{array}$ & $\begin{array}{l}-1.04 \\
(0.824)\end{array}$ & $\begin{array}{l}-1.73 \\
(0.696)\end{array}$ & $\begin{array}{l}0.24 \\
(0.957)\end{array}$ \\
\hline Supported Trump (\%) & 14.7 & $\begin{array}{l}-0.32 \\
(0.924)\end{array}$ & $\begin{array}{l}3.54 \\
(0.296)\end{array}$ & $\begin{array}{l}0.58 \\
(0.563)\end{array}$ & $\begin{array}{l}1.80 \\
(0.571)\end{array}$ & $\begin{array}{l}0.93 \\
(0.771)\end{array}$ \\
\hline $\begin{array}{l}\text { F statistic } \\
\text { P-value }\end{array}$ & $\begin{array}{l}\text { N/A } \\
\text { N/A }\end{array}$ & $\begin{array}{l}0.76 \\
0.6717\end{array}$ & $\begin{array}{l}0.65 \\
0.7746\end{array}$ & $\begin{array}{l}0.57 \\
0.8399\end{array}$ & $\begin{array}{l}1.03 \\
0.4127\end{array}$ & $\begin{array}{l}0.47 \\
0.9108\end{array}$ \\
\hline
\end{tabular}

Our main analysis of vaccine uptake assessed whether the 3 video messages (CDPH, safety or health consequences), financial incentives, or the link to the easy vaccination appointment scheduler increased a respondent's vaccination status within 30-days relative to the control group. We also assessed whether 30-day vaccination intentions increased in response to either of 
the 3 video messages. Following our pre-registered analysis, we estimate both outcomes using ordinary least-squares (OLS) regressions.

\section{Vaccinations}

In the control group, $8.82 \%$ of respondents were vaccinated, meaning they received at least one SARS-CoV-2 vaccine dose within 30 days of survey completion. Figure 1, which plots $\beta_{1}, M$, and $\beta_{3}$ from the estimation of equation (1) shows that none of the treatments improve upon this rate. The treatment effect estimates are small and close to zero. Only the CDPH and the safety videos are even positively related to 30 -day vaccination status. The upper $95 \%$ confidence intervals for financial incentives and the health consequences videos rule out increases in vaccination rates larger than 1.0 and 1.6 percentage points, respectively. The upper $95 \%$ confidence intervals for the CDPH and safety messages as well as the scheduling link are larger but still rule out increases larger than 3.0, 3.4 and 1.9 percentage points, respectively. We cannot reject that the impacts of the $\$ 10$ and $\$ 50$ incentives are the same. When fitted to a probit model, the effect sizes are similar in magnitude but with generally smaller standard errors/tighter confidence intervals (see SI Table S1).

Results of heterogeneity analyses, which stratified the regressions by age, gender, race/ethnicity, and 2020 presidential candidate support, were generally similar to the overall result in finding no meaningful effect of the treatments on vaccinations. The one exception was financial incentives, which reduced vaccination rates in both older individuals (ages 40 and over) and those indicating that they supported Trump in the 2020 presidential election (see SI Table S2). For respondents ages 40 and over, 30-day vaccination rates declined by 4.5 percentage points $(p=0.045)$ and 4.7 percentage points $(\mathrm{p}=0.041)$ in response to the $\$ 10$ and $\$ 50$ incentives, respectively. For respondents who indicated they supported Trump in the 2020 presidential election, the $\$ 50$ incentive decreased vaccination rates by 4.2 percentage points $(\mathrm{p}=0.047)$.

\section{Vaccination Intentions}

As shown in Figure 2, the video messages have large, positive impacts on vaccination intentions but do not affect actual vaccination rates. Vaccination intentions increase by 5.5 percentage points $(p=0.002)$ in response to the safety videos and 8.6 percentage points $(p<0.001)$ in response to the health consequences videos compared to the $34.1 \%$ probability (SD $33.8 \%$ ) control group respondents put on their likelihood of getting vaccinated in the 30 days after survey completion. Similar results are obtained when the data is fitted to a Tobit model (see SI Table 3)

In contrast to actual vaccinations, the impact of the videos across demographic groups is typically positive and shows significant variation by subgroup (see SI Table 4). As shown in Figure 2, these results imply at best a weak link between survey-elicited SARS-CoV-2 vaccinations intentions and actual vaccinations.

This is further supported by regression analysis that indicates that the overall relationship between actual SARS-CoV-2 vaccinations and vaccination intentions is weak with a 10percentage point increase in vaccination intention associated with only a 1.5 percentage point $(\mathrm{p}<0.001)$ increase in actual vaccination (see SI Table S5).

\section{Effect of Gender and Race Concordant Physicians}

For the two physician videos, we were able to analyze the impact of gender and race 
concordance/discordance (see SI Table S6). Assignment to a gender-discordant physician (see Panel A of SI Table S6) decreased 30-day vaccination rates for the health-consequences message by 2.9 percentage points $(\mathrm{p}=0.052)$. This difference was found to be driven by individuals under age 40, by men of all ages, and by Latinx members (see SI Figure S3). For respondents below age 40 of either gender, watching a negatively framed message about the potential health consequences of not getting vaccinated recorded by a gender discordant physician led to a 4.3 percentage point $(\mathrm{p}=0.010)$ decrease in 30 -day vaccination rates. For men, watching the negatively-framed message recorded by a female physician decreased vaccination rates by 5.8 percentage points $(\mathrm{p}=0.033)$. For Latinx, a gender discordant negatively framed video decreased 30 -day vaccination rates by 5.4 percentage points $(\mathrm{p}=0.045)$. In exploratory analysis, the effect size for young men was found to be over 10.0 percentage points $(\mathrm{p}=0.012)$. Race concordance did not affect vaccinations for either of two physician-recorded messages (see Panel B of SI Table S6).

Race and gender concordance of the physician had no effect on subject's vaccination intention (see SI Table 7).

\section{Discussion}

The main contribution of our study is to provide rigorous evidence on the question of whether behavioral nudges can increase vaccine uptake among the vaccine hesitant. The one previous RCT that analyzed the impact of behaviorally-informed reminder messages on SARS-CoV-2 vaccinations (14) was fielded during a period when eligibility was limited and vaccines were scarce. Likewise, the one prior RCT that studied the impact of financial incentives on SARSCoV-2 vaccinations (15) was fielded in Sweden, a country with very low rates of SARS-CoV-2 vaccine hesitancy (26) and during the period immediately after participants first became eligible for vaccination. Thus, the results of these studies may not apply to individuals who have actively chosen to forgo SARS-CoV-2 vaccination after many months of eligibility and despite ample supply of vaccines. These key differences in target population likely explain why, despite messages that are effective in other contexts and double the sized financial incentives as used in Sweden, we find no impact of similar interventions.

By fielding our study in the late spring and summer of 2021, we were able to focus on those who, by their actions, were at least not eager to get a SARS-CoV-2 vaccination. In this population, nudges appear largely ineffective at increasing vaccine uptake.

Our study also provides some suggestive evidence on the potential for financial incentives and messaging to backfire. Some experts worry that financial incentives and other perks may have the perverse effect of validating vaccine concerns among the SARS-CoV-2 vaccine hesitant because they are not typically used for other vaccination campaigns $(27,28)$. The results of our heterogeneity analysis suggest that financial incentives may have had this effect for stillunvaccinated individuals who are aged 40 and those who supported Trump in the 2020 presidential election. Similarly, negatively framed messages that emphasize the direct health consequences of SARS-CoV-2 infection have been controversial, with some concerned about the potential backlash among the unvaccinated $(27,28$,). Consistent with this hypothesis, we find evidence that such negatively framed messages may decrease vaccinations for men and those under 40 , depending on the messenger. 
Our work further speaks to the potential role of public health messengers. Public health messages from a race concordant messenger have shown promise in increasing influenza vaccinations (29). In the context of COVID-19, race-concordance has had mixed effects on information-seeking about COVID-19 among Black patients in some studies $(30,31)$, and no effect on COVID-19 knowledge or self-protective behaviors (31). We find no impact of race concordance on vaccine uptake or vaccination intentions. On the other hand, we find that negatively framed public health messages delivered by a gender discordant messenger reduces vaccine uptake for some groups, specifically males of all ages and adults under age 40 of either gender.

A final contribution of our study is to shed light on the relationship between vaccination intentions and actual vaccinations in the context of SARS-CoV-2. Vaccination intentions have been widely studied during the pandemic to help us understand and counter vaccine hesitancy $(32,33,34)$. Unlike in other contexts, such as influenza vaccination, $(9,29)$ however, we find the link between an individual's SARS-CoV-2 vaccination intention and actual vaccination status is weak, with messaging induced changes in vaccine intention not reflected in vaccine outcomes and vice-versa.

Our study has several limitations. First, because the survey was conducted online and recruitment was conducted by email or text, participants must have internet access and either an email account or mobile phone capable of receiving text messages. Second, given subjects were recruited from a single public Medicaid managed care plan and a single state, our findings may not generalize beyond our subject population.

Despite these limitations, our findings provide several lessons for more effective, evidence-based policy making on SARS-CoV-2 vaccinations. First, while vaccination intention studies may be an expedient way to understand the impact of different policy options and can be illuminating in other contexts, such studies may have limited value for SARS-CoV-2 vaccinations. Our work demonstrates a very weak link between self-stated SARS-CoV-2 vaccination intentions and subsequent vaccinations. In some cases, self-stated vaccination intentions are a misleading indicator of how actual vaccinations respond to messaging, providing false positive or false negative estimates of intervention effectiveness. Our findings suggest that studies that rely on self-stated intentions with respect to SARS-CoV-2 vaccinations should, at a minimum, be interpreted with caution.

Second, many of the efforts that have proved popular in the past and in other contexts, including small financial incentives, are unlikely to convince a substantial share of the currently unvaccinated to get vaccinated and may, in fact, backfire. We should have realistic expectations of what nudges can and cannot achieve during this pandemic. This study suggests they are unlikely to yield the high vaccination rates needed to aid in producing seroprevalence levels that may be population protective by reducing transmission and morbidity of this novel virus (35). Reaching a goal of very high vaccination rates likely requires much stronger policy levers, such as employer rules or government mandates.

\section{References and Notes}

1. See https://covid.cdc.gov/covid-data-tracker/\#vaccination-trends 
2. Calculation based on CDC reports of $76.7 \%$ of adults ages 18 and over receiving at least one dose as of 6:00AM on September 22, 2021 and a population of 258.3 million. See https://covid.cdc.gov/covid-data-tracker/\#vaccinations_vacc-total-admin-rate-total and https://www.census.gov/library/stories/2021/08/united-states-adult-population-grew-faster-thannations-total-population-from-2010-to-2020.html

3. G. Troiano, A. Nardi.Vaccine hesitancy in the era of COVID-19, Public Health. 2021 May;194:245-251. doi: 10.1016/j.puhe.2021.02.025.

4. The SAGE Vaccine Hesitancy Working Group. What influences vaccine acceptance: a model of determinants of vaccine hesitancy. 2013.

https://www.who.int/immunization/sage/meetings/2013/april/1_Model analyze driversofvaccine Confidence 22 March.pdf

5. Volpp, K. G., C. C. Cannuscio, Incentives for immunity - strategies for increasing covid-19 vaccine uptake. $N$ Engl J Med, 385, e1 (2021). doi: 10.1056/NEJMp2107719.

6. M. Ashworth, L. Thunström, T.L. Cherry, S.C. Newbold, D.C. Finnoff, Emphasize personal health benefits to boost COVID-19 vaccination rates, Proc. Natl. Acad. Sci. U.S.A., 118 (2021) doi: $10.1073 /$ pnas.2108225118.

7. C. J. Davis, M Golding, R McKay, Efficacy information influences intention to take COVID19 vaccine, Br J Health Psychol, (2021) doi: 10.1111/bjhp

8. M. Motta, S. Sylvester, T. Callaghan, K Lunz-Trujillo. Encouraging COVID-19 Vaccine Uptake Through Effective Health Communication, Front Polit Sci, (2021) doi:

10.3389/fpos.2021.630133.

9. E.T. Bronchetti, D.B. Huffman, E. Magenheim, Attention, intentions, and follow-through in preventive health behavior: Field experimental evidence on flu vaccination. J Econ Behav Organ, 116 (2015), 270-291.

10. K. L. Milkman, J. Beshears, J. J. Choi, D. Laibson, B. C. Madrian, Using implementation intentions prompts to enhance influenza vaccination rates. Proc. Natl. Acad. Sci.

U.S.A. 108, 10415-10420 (2011).

11. G. B. Chapman, M. Li, H. Colby, H. Yoon, Opting in vs opting out of influenza vaccination. JAMA 304, 43-44 (2010).

12. D. Yokum, J. C. Lauffenburger, R. Ghazinouri, N. K. Choudhry, Letters designed with behavioural science increase influenza vaccination in Medicare beneficiaries. Nat.

Hum. Behav. 2, 743-749 (2018).

13. K. L. Milkman, M. S. Patel, L Gandhi, H. N. Graci, D. M. Gromet, H. Ho, J. S. Kay, T. W. Lee, M. Akinola, J. Beshears, J. E. Bogard, A. Buttenheim, C. F. Chabris, G. B. Chapman, J. J. Choi, H. Dai, C. R. Fox, A. Goren, M. D. Hilchey, J. Hmurovic, L.K. John, D. Karlan, M. Kim, D. Laibson, C. Lamberton, B. C. Madrian, M. N. Meyer, M. Modanu, J. Nam, T. Rogers, R. Rondina, S. Saccardo, M. Shermohammed, D. Soman, J. Sparks, C. Warren, M. Weber, R. Berman, C. N. Evans, C. K. Snider, E. Tsukayama, C. Van den Bulte, K. G. Volpp, A. L. Duckworth A megastudy of text-based nudges encouraging patients to get vaccinated at an upcoming doctor's appointment Proc. Natl. Acad. Sci. U.S.A. 118 (20) e2101165118 (2021); DOI: 10.1073/pnas.2101165118.

14. H. Dai, S. Saccardo, M.A. Han, M.A. et al. Behavioural nudges increase COVID-19 vaccinations. Nature (2021). https://doi.org/10.1038/s41586-021-03843-2

15. P. Campos-Mercade, A. N. Meier, F. H. Schneider, S. Meier, D. Pope, E. Wengström, Monetary incentives increase COVID-19 vaccinations, Science 10.1126/science.abm0475 (2021). 
16. Walkey AJ, Law A, Bosch NA. Lottery-Based Incentive in Ohio and COVID-19 Vaccination Rates. JAMA. 2021;326(8):766-767. doi:10.1001/jama.2021.11048

17. Neil K.R. Sehgal, Impact of Vax-a-Million lottery on COVID-19 vaccination rates in Ohio, The American Journal of Medicine, 2021, forthcoming, doi: 10.1016/j.amjmed.2021.06.032

18. See https://www.census.gov/quickfacts/fact/table/contracostacountycalifornia/PST045219

19. See https://www.latimes.com/projects/california-coronavirus-cases-tracking-outbreak/covid19-vaccines-distribution/ As of October 5, 2021, 72.4\% of residents in Contra Costa county were fully vaccinated and had the $5^{\text {th }}$ highest county vaccination rate in the State. It has been in the top 5 or higher since early on in the State vaccination campaign.

20. Contra Costa County opened up eligibility on March 30, 2021. See https://cchealth.org/pressreleases/2021/0330-Contra-Costa-Opens-Eligibility-to-those-16plus.php

21. The state opened up eligibility to all adults on April 15, 2021. See

https:/www.gov.ca.gov/2021/04/15/all-californians-16-now-eligible-for-covid-19-vaccines/

22. Z. Horne, D. Powell, J. E. Hummel, K. J. Holyoak. Countering antivaccination attitudes.

Proc. Natl. Acad. Sci. U.S.A, 112, 10321-10324 (2015). doi:10.1073/pnas.1504019112.

23. Due to fluency concerns, the videos for the English and Spanish (male) Latino videos were recorded by two different physicians.

24. See https://www.kff.org/medicaid/state-indicator/medicaid-enrollment-by-gender and https://data.chhs.ca.gov/dataset/medi-cal-certified-eligibles-tables-by-county-from-2010-tomost-recent-reportable-month/resource/cc08b60f-393f-4e37-9b3e-976d7a9f2a72

25. Two exceptions to individual significance are the share impaneled for the safety video and financial incentives condition. A coding error during the early phase of the study, when only the impaneled were recruited, randomly assigned members at 1:1:1 instead of a $2: 1: 1$ ratio to no financial incentives, a \$10 incentive and a \$50 incentive. This led to a disproportionate share of the impaneled receiving financial incentives.

26. See https://www.folkhalsomyndigheten.se/nyheter-och-press/nyhetsarkiv/2021/maj/fortsattstor-vilja-att-vaccinera-sig-mot-covid-19/

27. P. Hsieh. Perks and incentives for COVID-19 Vaccination May Backfire, Forbes May 28, 2021. https://www.forbes.com/sites/paulhsieh/2021/05/28/perks-and-incentives-for-covid-19vaccination-may-backfire/?sh $=4 \mathrm{fa} 783 \mathrm{f} 726 \mathrm{~b} 1$

28. G. Lowenstein, C. Cryder. Why paying people to be vaccinated could backfire, New York Times December 14, 2020. https://www.nytimes.com/2020/12/14/upshot/covid-vaccinepayment.html

29. M. Alsan, O Garrick, G. Graziani. 2019. Does diversity matter for health? Experimental evidence from Oakland. Am Econ Rev. 109(12): 4071-4111 (2019).

30. M. Alsan, F.C. Stanford, A. Banerjee, E. Breza, A.G. Chandrasekhar, S. Eichmeyer, P. Goldsmith-Pinkham, L. Ogbu-Nwobodo, B.A. Olken, C. Torres, A. Sankar, P.L. Vautrey, E. Duflo. Comparison of Knowledge and Information-Seeking Behavior After General COVID-19 Public Health Messages and Messages Tailored for Black and Latinx Communities: A Randomized Controlled Trial. Ann Intern Med. 2021 Apr;174(4):484-492. doi: 10.7326/M206141.

31. C. Torres, L. Ogbu-Nwobodo, M. Alsan, F.C. Stanford, A. Banerjee, E. Breza, A.G. Chandrasekhar, S. Eichmeyer, M. Karnani, T. Loisel, P Goldsmith-Pinkham, B.A. Olken, P.L. Vautry, E. Warner, E. Duflo. Effect of Physician-Delivered COVID-19 Public Health Messages and Messages Acknowledging Racial Inequity on Black and White Adults' Knowledge, Beliefs, and Practices Related to COVID-19: A Randomized Clinical Trial. JAMA Netw Open. 
2021;4(7):e2117115. doi:10.1001/jamanetworkopen.2021.17115.

32. COVID-19 vaccine PSA criticized as too 'graphic' and offensive' New York Post, July 12, 2021 https://nypost.com/2021/07/12/aussie-covid-19-ad-criticized-as-insensitive-and-graphic/ 33. R. Mogul, Australian ad showing Covid patient gasping for air sparks backlash as country battles Delta variant," CNN, July 12, 2021 https:/www.cnn.com/2021/07/12/australia/covid-adbacklash-australia-intl-hnk/index.html

34. F. Newport, Vaccine Hesitancy and U.S. Public Opinion, Gallup, July 30, 2021. https://news.gallup.com/opinion/polling-matters/352976/vaccine-hesitancy-public-opinion.aspx 35. C. Aschwanden. Five reasons why COVID herd immunity is probably impossible, Nature, March 18, 2021 https://www.nature.com/articles/d41586-021-00728-2

Acknowledgments: Research reported in this paper was supported by J-PAL North America's State and Local Innovation Initiative as well as the National Institute on Aging of the National Institutes of Health under Award Number P30AG034532. The content is solely the responsibility of the authors and does not necessarily represent the official views of J-PAL North America or the National Institutes of Health. We also are grateful for extremely helpful feedback from Marcella Alsan, Wandi Bruine de Bruin, Michael Hallsworth, Elana Safran, Anya Samek, Swaroop Samek, and Mattie Toma as well as participants at the National Bureau of Economic Research's COVID-19 and Health Outcomes Spring Conference on June 16, 2021 and from ongoing support from Joe Doyle and Sarah Holmes Berk.

\section{Funding:}

J-PAL North America State and Local Innovation Initiative

NBER Roybal Center grant, 5P30AG034532

\section{Author contributions:}

Conceptualization: TYC, MS, RS, SBS, MJ

Methodology: TYC, MS, MJ

Investigation: TYC, MS, MJ

Visualization: TYC, MJ

Funding acquisition: MJ, TYC, MS

Project administration: MJ

Writing - original draft: TYC, MJ, MS

Writing - review \& editing: TYC, MS, RS, SBS, MJ

Competing interests: Authors declare that they have no competing interests.

Data and materials availability: Data from this work will be made public upon acceptance. 


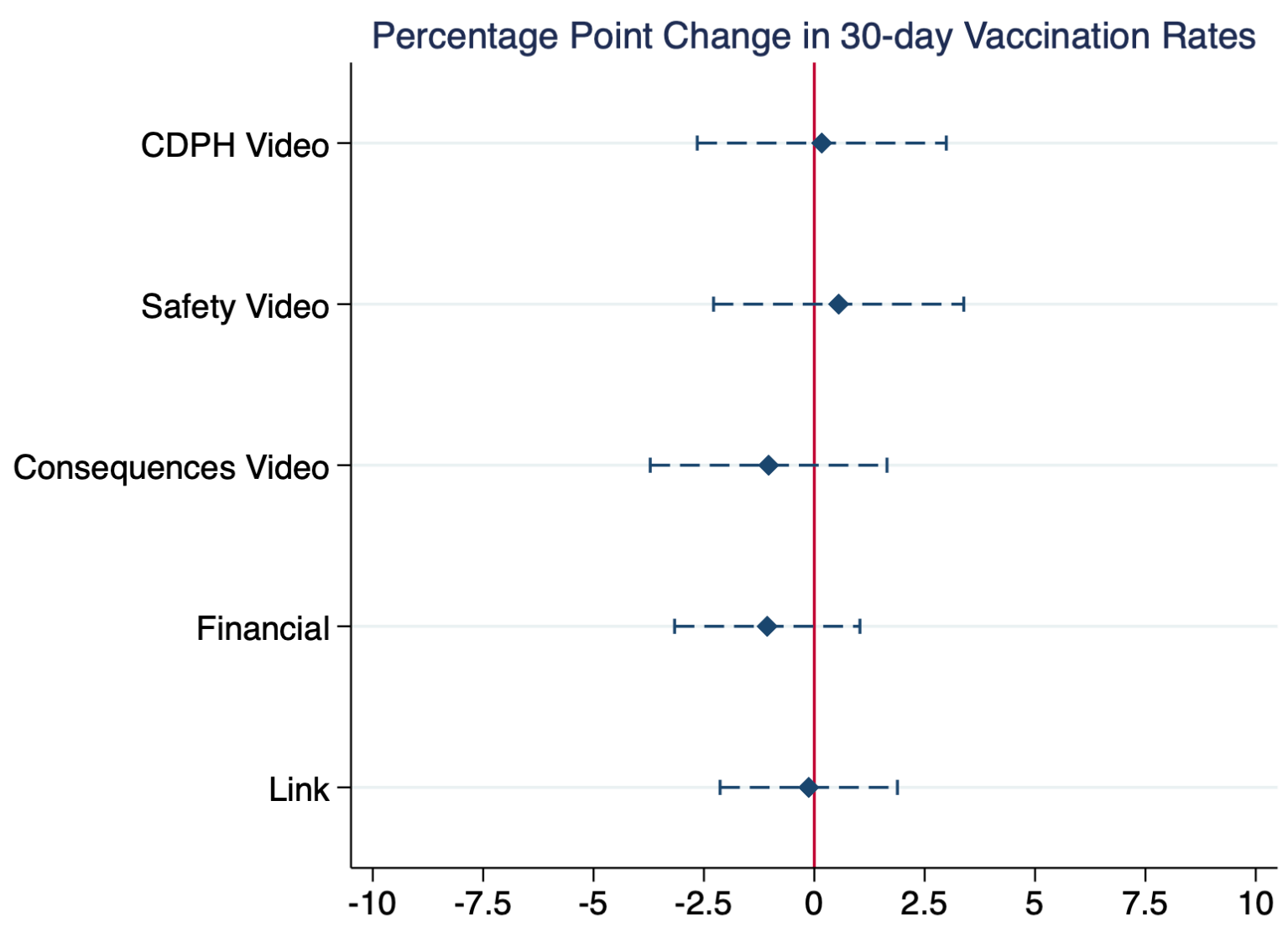

Fig. 1. Impact of Main Treatments on 30-day Vaccination Rates Regression-estimated change in SARS-CoV-2 vaccinations induced by each of our main behavioral interventions compared to control. Dashed whiskers depict 95\% CIs. 


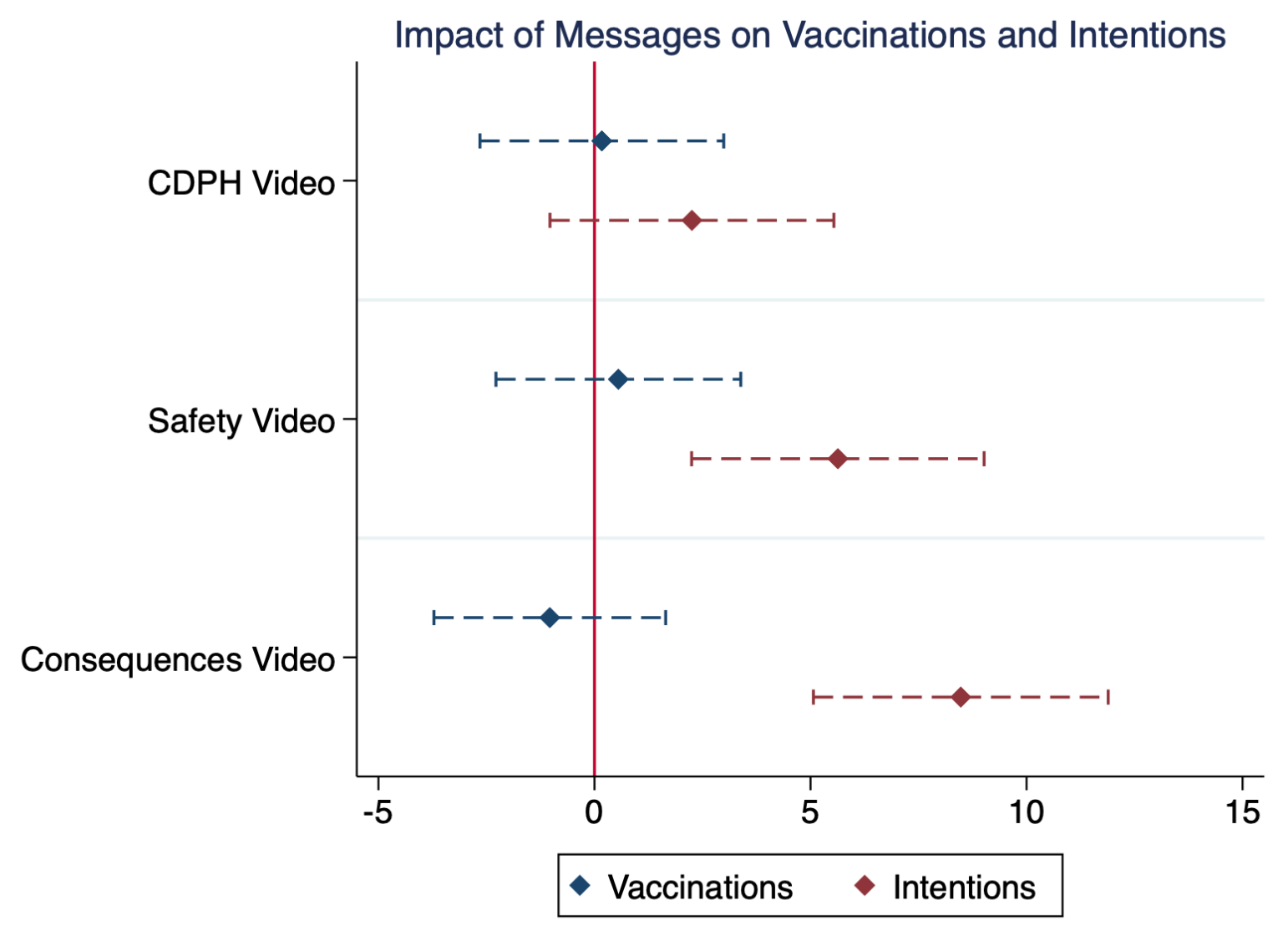

Fig. 2. Percentage Point Change in Vaccination Rates and Intentions due to Video Messages. Comparison of regression-estimated change in SARS-CoV-2 vaccinations (in blue) and vaccinations intentions (in red) induced by each of the three different public health video messages compared to control. Dashed whiskers depict 95\% CIs. 